\title{
Significantly enhanced tensile strength and ductility in nickel aluminium bronze by equal channel angular pressing and subsequent heat treatment
}

\author{
C. J. Barr*, D. T. McDonald, and K. Xia* \\ Department of Mechanical Engineering and Defence Materials Technology Centre, The University \\ of Melbourne, Victoria 3010, Australia
}

\begin{abstract}
Nickel aluminium bronze (NAB) was subjected to equal channel angular pressing at $400^{\circ} \mathrm{C}$ for up to four passes in routes $\mathrm{B}_{\mathrm{A}}$ and $\mathrm{C}$, respectively, followed by isothermal heat treatment with a view to improving the $\kappa$ phase structures and tensile properties. The lamellar $\kappa_{\text {III }}$ structure was completely broken after 4 passes in route $\mathrm{B}_{\mathrm{A}}$ although route $\mathrm{C}$ was less efficient. Spheroidisation and coarsening of the highly deformed $\kappa_{\mathrm{III}}$ continued during heat treatment especially at $\geq 600^{\circ} \mathrm{C}$. At $800^{\circ} \mathrm{C}$, both the lamellar structure and the fine $\kappa_{\mathrm{IV}}$ particles transformed completely into a coarse globular morphology with no distinction between the primary and eutectoid $\alpha$. Significant increases in strength were achieved by ECAP, reaching a maximum yield strength of $960 \mathrm{MPa}$ with a good ductility of $\sim 14 \%$. Heat treatment after ECAP was shown to considerably improve tensile ductility to $>30 \%$ while keeping the strength high at $\sim 700 \mathrm{MPa}$, a significant enhancement compared to the as-received NAB.
\end{abstract}

Keywords: Equal channel angular pressing, severe plastic deformation, lamellar structure, spheroidisation, tensile properties.

* Corresponding authors: c.barr2@student.unimelb.edu.au, $\underline{\text { k.xia @ unimelb.edu.au }}$ 


\section{Introduction}

Nickel aluminium bronze (NAB) is a copper based alloy which finds wide use in the marine industry thanks to its unique combination of high strength, corrosion resistance and protection against befouling $[1,2]$. The impressive corrosion resistance of aluminium bronzes has been linked to the quick formation of a protective sub-layer of $\mathrm{Al}_{2} \mathrm{O}_{3}$ which hampers ionic transport of cuprous ions to the surface layer of $\mathrm{Cu}_{2} \mathrm{O}$ [1]. Compared to the single $\alpha$-phase alloys, additions of up to 5 wt.\% $\mathrm{Ni}$ and $5 \mathrm{wt} . \% \mathrm{Fe}$ in NAB improve both strength and corrosion resistance by allowing higher concentrations of aluminium whilst suppressing formation of the adverse $\gamma_{2}$ phase which accelerates corrosion [2]. However, these additions also lead to a complex microstructure consisting of several distinct phases including the large rosettes of $\mathrm{Fe}_{3} \mathrm{Al}$ denoted as $\kappa_{\mathrm{I}}$ or $\kappa_{\mathrm{II}}$ (distinguishable by size and location [3]), the lamellar NiAl based $\kappa_{\text {III }}$ phase forming a eutectoid structure, and the fine $\mathrm{Fe}_{3} \mathrm{Al}$ based $\kappa_{\mathrm{IV}}$ precipitates in the primary $\alpha$ matrix $[2,3]$. These intermetallic phases cause several complications in both mechanical and corrosion performances. Easy paths for crack propagation may be found along $\kappa_{\mathrm{I}}$ and $\kappa_{\mathrm{II}}$ boundaries [4], limiting the ductility of cast components. The larger $\kappa_{\mathrm{I}}$ and $\kappa_{\mathrm{II}}$ rosettes are also known to pull out during cavitation attack under turbulent flow conditions [5]. More significantly, selective phase corrosion along the $\alpha-\kappa_{\text {III }}$ interface leads to deterioration of the surface [1,6], and can penetrate deep beneath the surface under crevice corrosion conditions [7]. It is expected that by eliminating the lamellar structure of $\kappa_{\mathrm{III}}$ and strengthening the $\alpha$ matrix, both corrosion and cavitation properties can be improved. Whaton et al. made such observations in wrought NAB which contained little $\kappa_{\text {III }}[1]$, although no direct comparison between the corrosion properties of wrought and cast NAB was made.

With the advent of severe plastic deformation (SPD) techniques, new possibilities for enhancing the corrosion resistance of NAB become available $[6,8,9]$, with the added benefit of ultra high strength through grain refinement [10-14]. This idea is supported by a recent study on the surface modification of NAB by friction stir processing [6], in which the corrosion rate was 
significantly decreased through a combination of grain refinement and homogenisation of the $\kappa$ phases. However, the refinement offered by friction stir processing is limited to the surface layer and no strengthening is provided to the bulk of the material. Equal channel angular pressing (ECAP), on the other hand, is now widely accepted as a SPD process for the production of bulk ultrafine grained materials [10]. ECAP has also been shown to be effective in refining lamellar structures, either through shear based transformations [15] or spheroidisation during post-ECAP heat treatment [16-18]. To date, no investigations on the mechanical properties of ultrafine grained NAB have been published although the properties of other aluminium bronzes processed by ECAP are promising. In a series of studies by An et al. [12-14], the yield strength of an aluminium bronze increased significantly from $\sim 70 \mathrm{MPa}$ in the coarse grained material, to over $700 \mathrm{MPa}$ after ECAP. Such strengthening in NAB would be highly beneficial, not only in boosting the performance of the NAB components, but also in potentially replacing some stainless steel components which may suffer from galvanic corrosion. However, limited dislocation storage in ultrafine grained materials resulted in little or no work hardening and a tendency for the early onset of plastic instability [10-12, 19]. The instability can be mitigated by post ECAP heat treatment at the cost of strength, but this does not always result in an increase in ductility [13,14]. The purpose of this paper is threefold: (1) to eliminate the lamellar structure in NAB using ECAP, (2) to further modify the microstructure through the use of post-ECAP heat treatment, and (3) to achieve a combination of high strength and good ductility in NAB through the use of ECAP and heat treatment.

\section{Experimental material and procedures}

A cast NAB plate with a composition of $\mathrm{Cu}-8.8 \mathrm{Al}-4.4 \mathrm{Fe}-5.2 \mathrm{Ni}-1.1 \mathrm{Mn}$ was supplied by VEEM Australia, after heat treatment at $675^{\circ} \mathrm{C}$ for $6 \mathrm{~h}$. Such heat treatment is necessary to fully transform any retained $\beta^{\prime}$ phase into $\alpha+\kappa_{\text {IIII }}$, and is known to improve corrosion resistance [2]. The plate was machined into bars of $8 \times 8 \times 10 \mathrm{~mm}$ for ECAP. These specimens were wrapped in 
graphite and inserted into a $90^{\circ}$ ECAP die with a cross section of $9 \times 9 \mathrm{~mm}$ and inner and outer curvatures of 5 and $3 \mathrm{~mm}$, respectively. The die was then heated to $400^{\circ} \mathrm{C}$. After the temperature stabilised, pressing was conducted at $5 \mathrm{~mm} / \mathrm{min}$. In addition to a forward plunger in the entrance channel, a secondary back plunger was placed in the exit channel to provide a constant back pressure of $50 \mathrm{MPa}$ during ECAP. Samples were pressed to a maximum of 4 passes using routes $\mathrm{B}_{\mathrm{A}}$ (alternate $90^{\circ}$ rotation of the sample between passes) and $\mathrm{C}\left(180^{\circ}\right.$ rotation between passes), respectively and quenched in water upon retrieval from the die. The ECAP processed specimens were sectioned into small samples for a series of isothermal heat treatments at temperatures between 300 and $800^{\circ} \mathrm{C}$ for a duration of $1 \mathrm{~h}$, followed by water quenching.

Vickers microhardness (HV) was measured using an indenter load of $500 \mathrm{~g}$ and a dwell time of 15 s. Microstructural analysis was carried out using scanning electron microscopy (SEM) on samples prepared using standard metallography procedures. Tensile specimens possessing a gauge length of $6 \mathrm{~mm}$ and a cross section of $2 \times 3 \mathrm{~mm}$ were tested at room temperature with an initial strain rate of $1 \times 10^{-3} \mathrm{~s}^{-1}$ and the displacement measured using a laser extensometer.

\section{Results}

\subsection{Microstructures}

The as-received NAB microstructure is presented in Fig. 1 showing the eutectoid structure containing $\kappa_{\text {III }}$ lamellae, large $\kappa_{\text {II }}$ rosettes mostly located inside the eutectoid region, and fine precipitates of $\kappa_{I V}$ in a matrix of primary $\alpha$. The lamellae in the as-received material were randomly oriented as $\kappa_{\mathrm{III}}$ is known to grow perpendicular to the primary $\alpha$ boundaries [2]. Fig. 2 depicts the microstructure after one pass of ECAP, with the lamellar orientations becoming highly directional. In particular, much of the lamellar $\kappa_{\mathrm{III}}$ was fragmented (arrow 1 and inset in Fig. 2a) and formed streams oriented close to $22.5^{\circ}$ to the longitudinal direction of the exit channel (Fig. 2a), coinciding 
with the principal strain direction for an ideal, sharp-cornered $90^{\circ}$ ECAP die [20]. Spheroidised $\kappa_{\text {III }}$, identifiable by the surrounding area of $\kappa_{\mathrm{IV}}$ free eutectoid $\alpha$, was also observed between the streams of fragments (arrow 2 in Fig. 2a). Perpendicular to the principal strain direction, the $\kappa_{\text {III }}$ lamellae remained straight in the larger colonies consisting of a high number of laths (hollow arrow in Fig. 2b.) but those in smaller colonies buckled with a similar distortion pattern between adjacent laths (solid arrows in Fig. 2b).

The microstructures after 4 passes with route $C$ and route $B_{A}$ are shown in Fig. 3 and Fig 4, respectively. After the 4th pass in route C (Fig. 3), the directionality seen after the first pass reverted to the random orientations in the as-received state. However, the lamellar structure was altered in different ways with some $\kappa_{\text {III }}$ spheroidised (arrow 1), some $\kappa_{\text {III }}$, although fragmented, forming lamellae again after redundant straining (arrow 2 and inset), and others fragmented and dispersed, i.e. not re-forming lamellae (arrow 3). In addition, some $\kappa_{\text {II }}$ particles appeared to have collided (arrow 4). In contrast, the lamellar structure was completely transformed into fragmented and spheroidised $\kappa_{\text {III }}$ after four passes in route $B_{A}$ (Fig. 4) with the fragmented $\kappa_{\text {III }}$ streams maintaining the alignment with the principal strain direction. The homogeneity of the microstructure was significantly improved from the as-received material, with the $\kappa_{\text {III }}$ particles now comparable in size to the fine $\kappa_{\mathrm{IV}}$ precipitates. The morphology of $\kappa_{\mathrm{II}}$ was also influenced, evolving from the round shape in the as-received material to highly irregular (arrows in Fig. 4).

The microstructures following one pass of ECAP and then heat treatment at 600, 700 and $800^{\circ} \mathrm{C}$ for one hour are shown in Figs. 5a, 5b and $5 \mathrm{c}$, respectively (there was little change at temperatures below $600^{\circ} \mathrm{C}$ ). Slight coarsening (arrow 1 in Fig. 5a) of the fragmented $\kappa_{\mathrm{III}}$ and perturbations (arrow 2 and inset) along the distorted lamellae occurred at $600^{\circ} \mathrm{C}$, indicating the start of the spheroidisation process. At the higher temperature of $700^{\circ} \mathrm{C}$, the undistorted lamellae (arrow 1 in Fig. 5b) remained with the majority of the $\kappa_{\text {III }}$ fragments now perfectly rounded following spheroidisation and coarsening (arrow 2). Coarsening of $\kappa_{\mathrm{IV}}$ was also apparent, reducing the 
number of fine precipitates in the primary $\alpha$. At $800^{\circ} \mathrm{C}$, little distinction between the primary and eutectoid $\alpha$ could be made as all of the fine $\kappa_{\mathrm{IV}}$ had coarsened into large particles leaving precipitate free $\alpha$ behind. The lamellar $\kappa_{\text {III }}$ was also no longer recognisable, as it had coarsened into partially elongated particles (arrow 1 in Fig. 5c). In some cases, these particles were seen to have sharp, angular edges (arrows 2 and 3).

The microstructures following ECAP for 4 passes with route $\mathrm{B}_{\mathrm{A}}$ and heat treatment at $600^{\circ} \mathrm{C}$, $700^{\circ} \mathrm{C}$ and $800^{\circ} \mathrm{C}$ are shown in Figs. $6 \mathrm{a}, 6 \mathrm{~b}$ and $6 \mathrm{c}$, respectively. As the lamellar structure had already been broken during ECAP, only coarsening of the spheroidised lamellar fragments was observed at $600^{\circ} \mathrm{C}$ and $700^{\circ} \mathrm{C}$. At $800^{\circ} \mathrm{C}$, the microstructure was nearly identical to that after one pass and heat treatment (Fig. 5c), although the coarsened globular $\kappa_{\mathrm{III}}$ appeared slightly more angular.

\subsection{Microhardness}

The HV versus number of ECAP passes is plotted in Fig. 7. The hardness increased significantly from $210 \mathrm{HV}$ in the as-received material to $\sim 315 \mathrm{HV}$ after the first pass. The microhardness of route $\mathrm{C}$ was seen to fluctuate with subsequent passes, becoming slightly softer on even numbered passes, and harder on odd passes. This was not apparent for route $\mathrm{B}_{\mathrm{A}}$, which maintained a high hardness until the fourth pass, where it was seen to drop. The variation in hardness after ECAP was relatively small, with a standard deviation for all samples of $\sim 4.8$. The hardness following heat treatment at various temperatures is shown in Figs. $8 \mathrm{a}$ and $8 \mathrm{~b}$ for the two routes, respectively. Little change in hardness was observed below $400^{\circ} \mathrm{C}$ for all ECAP conditions. The S-shape curve indicative of the occurrence of recovery and recrystallisation processes is only well defined for the single pass sample, and the curves became more linear above $400^{\circ} \mathrm{C}$ with increasing passes. This is particularly the case for route $\mathrm{B}_{\mathrm{A}}$ (Fig. 8 b). At $800^{\circ} \mathrm{C}$, all samples had softened below the hardness of the as-received material. 


\subsection{Tensile properties}

The tensile stress-strain curves for NAB after ECAP for 1, 2 and 4 passes at $400^{\circ} \mathrm{C}$ are shown in Figs. 9a and $9 \mathrm{~b}$ for routes $\mathrm{C}$ and $\mathrm{B}_{\mathrm{A}}$, respectively. A significant jump in strength was observed after the first pass, with the yield stress increasing from $\sim 180 \mathrm{MPa}$ in the as-received material to $\sim 960 \mathrm{MPa}$, accompanied by a significant reduction in ductility from $\sim 24 \%$ to $\sim 5 \%$. After two passes, the sample processed by route $\mathrm{B}_{\mathrm{A}}$ showed a continued increase in strength and ductility, rising to $\sim 970 \mathrm{MPa}$ and $\sim 6 \%$, respectively. This was in contrast to route $\mathrm{C}$, which showed a slight reduction in strength to $\sim 950 \mathrm{MPa}$ with only a minor change in ductility. The difference in ductility became greater after 4 passes, with route $\mathrm{B}_{\mathrm{A}}$ leading to a considerably improved elongation of $\sim 14 \%$ (mostly during strain softening). The large increase in ductility of the route $\mathrm{B}_{\mathrm{A}}$ sample did not coincide with any significant drop in yield stress, which remained close to $960 \mathrm{MPa}$, although the UTS was noticeably lower. Again, little change was observed in route C, which maintained a yield strength and ductility of $\sim 930 \mathrm{MPa}$ and $\sim 6 \%$.

The tensile stress-strain curves after isothermal heat treatment at 450 to $700^{\circ} \mathrm{C}$ are shown in Figs. 10a, 10b and 10c for the materials ECAP processed for 1, 2 and 4 passes with $\mathrm{B}_{\mathrm{A}}$, respectively. A general trend, as expected, is that the strength was decreased and ductility increased as the heat treatment temperature was increased. However, heat treatment at the relatively low temperature of $450^{\circ} \mathrm{C}$ resulted in no improvement in ductility in the sample processed for 1 pass, and some moderate improvements in the samples processed for 2 and 4 passes. Although strength continued to drop with increasing temperature, the materials heat treated at 600 and $700^{\circ} \mathrm{C}$ exhibited superiority in both strength and ductility, especially in the 4-pass sample, compared to the asreceived material. The strain softening behaviour observed in the sample processed for one pass was eliminated at all temperatures. However, temperatures of 500 and $550^{\circ} \mathrm{C}$ were required to eliminate work softening in samples after ECAP processing for 2 and 4 passes, respectively.

\section{Discussion}




\subsection{Deformation behaviour of the lamellar $\kappa_{\text {III }}$ phase}

The streamed $\kappa_{\text {III }}$ fragments (arrow 1 in Fig. $2 a$ ) and the spheroidised $\kappa_{\text {III }}$ between them in the as-ECAP processed microstructure (arrow 2 in Fig. 2a) are unique. ECAP has been shown to cause deformation induced transformations in wholly lamellar microstructures such as eutectic Al$\mathrm{Cu}$ [15] and high carbon steels [18], where such transformations become necessary to account for the geometric distortions to the multidirectional lamellar structure. However, in the duplex structures consisting of eutectic or eutectoid lamellar colonies and primary phase grains, such as the pearlite plus ferrite structures in low [16] to medium carbon steels [17], the occurrence of ECAP induced spheroidisation is significantly less. Instead, the cementite lamellae were either stretched into fragments or compressed into curled, wavy laths $[16,17]$, depending on the initial orientation of the lamellae to the shear plane. This fragmentation could only be caused by a lengthening along the lamellar plane, as evidenced by the observed necking along the stretched cementite fragments $[16,17]$. Indeed, similar morphologies of $\kappa_{\text {III }}$ can be seen following ECAP deformation in the present investigation, although necking of the $\kappa_{\text {III }}$ is not readily observed (inset in Fig. 2a). In this case, the ductility of the eutectoid phase should be taken into account as NiAl (on which the $\kappa_{\text {III }}$ phase is based) shows little ductility at high strain rates $[21,22]$. This is in contrast to the ECAP of a $\mathrm{Cu}-\mathrm{Ag}$ alloy, where the softer and more ductile Ag precipitates were continually stretched into fine fibres after 4 passes in route A [23]. Furthermore, as analysed in [20], the maximum stretching occurs in the principal strain direction, and should coincide with the alignment of the fragmented streams, as observed here. Hence, both lengthening and low ductility in the eutectoid lamellae are required for their break down via fragmentation. On the other hand, maximum shortening occurs perpendicular to the principal strain direction. In both lamellar cementite and lamellar $\kappa_{\text {III }}$, such a contraction results in buckling of the laths, causing it to become warped or wavy. However, the extent of buckling in $\kappa_{\text {III }}$ is much greater than in cementite. This is possibly due to the difference in their lamellar spacings. In the as-received NAB, the lamellar spacing of $\kappa_{\mathrm{III}}$ was $\sim 650 \mathrm{~nm}$, 
compared to $160 \mathrm{~nm}$ for the cementite in [16]. As seen in Fig. 2b (solid arrows), the distortion in one lath is also experienced by neighbouring laths. When the lamellar spacing is reduced, the distortion must be shared over a larger number of laths, and this has been shown to increase the deformation resistance of the colony (as seen in the lower section of Fig. 2b).

\subsection{Spheroidisation of the lamellar $\kappa_{\text {III }}$ phase}

The consequence of the buckling is the creation of many highly curved sections of the $\kappa_{\text {III }}$ lamellae. It is well established that curved surfaces intrinsically have a higher chemical potential than flat ones [24], and thus are less stable. When the lamellae are buckled during ECAP, some sections with very high curvatures may possess enough driving energy to undergo spheroidisation even at the low ECAP temperature of $400^{\circ} \mathrm{C}$. This curvature-enhanced spheroidisation would continue during the subsequent heat treatment. Although at $600^{\circ} \mathrm{C}$ the overall changes appeared not significant, the highly curved segments found in the as-ECAP processed state are no longer existent. Increasing the temperature to $700^{\circ} \mathrm{C}$, only the straight lamellae survived the spheroidisation process. (The microstructure at $800^{\circ} \mathrm{C}$ cannot be entirely attributed to spheroidisation and will be discussed in the next section.) It can be concluded, therefore, that the streams of spheroidised $\kappa_{\text {III }}$ are actually a result of severe buckling which produces curvatures greater than needed by spheroidisation at $400^{\circ} \mathrm{C}$, leading to the break-up of the lamellae. The additional thermal energy provided by post ECAP heat treatment then allows the less deformed lamellae to spheroidise. Moreover, it should be remembered that the production of a large number of dislocations and vacancies during ECAP may also increase the speed of diffusion, accelerating the spheroidisation process.

\subsection{Dissolution of the $\kappa$-phases at $800^{\circ} \mathrm{C}$}

When heat treated at $800^{\circ} \mathrm{C}$, vastly different microstructures resulted. These microstructures are similar to the one obtained in a cast $\mathrm{NAB}$ after heat treatment at $860^{\circ} \mathrm{C}$ for $3 \mathrm{~h}$ and almost identical to the one treated at $840^{\circ} \mathrm{C}$ for $72 \mathrm{~h}$ [2]. In all the cases, little distinction could be made 
between primary and eutectoid $\alpha$, with the $\kappa$-phases all existing in coarse globular morphologies. The coarsening of the fine $\kappa_{\mathrm{IV}}$ precipitates into large globules may be due to its transformation from $\kappa_{\mathrm{IV}}$ to a high temperature $\kappa_{\mathrm{V}}$ phase [2]. Above $675^{\circ} \mathrm{C}$, the predominantly iron rich $\kappa_{\mathrm{IV}}$ begins to absorb nickel from its surroundings, eventually achieving equal amounts of the two elements. In doing so, the originally globular $\kappa_{\mathrm{IV}}$ transforms into a short lath morphology identified as $\kappa_{\mathrm{V}}$. Whereas $\kappa_{\mathrm{IV}}$ and/or $\kappa_{\mathrm{V}}$ coarsens gradually as the temperature is raised from $600^{\circ} \mathrm{C}$ to $800^{\circ} \mathrm{C}$, the $\kappa_{\mathrm{III}}$ phase shows a sudden change from fine fragments/spheroids to large, irregularly shaped particles at $800^{\circ} \mathrm{C}$. On closer inspection, the irregular shape appears to be formed by the borders of the surrounding $\alpha$ grains. The answer to this inconsistency may lie in the dissolution temperature of $\kappa_{\text {III }}$, thought to be close to $825^{\circ} \mathrm{C}$ [2]. At this temperature, the necessary diffusion for particle drag by grain boundaries may be achieved, and this has been shown to occur for precipitates similar in size to the finely fragmented $\kappa_{\text {III }}$ [25]. In heat treated high carbon steel processed by ECAP, it was shown that the spheroidised cementite was preferentially located at the triple points of the surrounding ferrite grains [18]. The same preferred location may also apply to the $\kappa_{\text {III }}$ fragments and spheroids. In this case, if particle drag were to occur through grain boundary migration, the fragments of $\kappa_{\mathrm{III}}$ would eventually coalesce as these triple points merge. This process would continue until the particle becomes too large to move. Coarsening of the coalesced $\kappa_{\text {III }}$ could still continue through Otswald ripening, and the growth may lead nearby clusters to impinge on one another at the interface [26]. Since the migration of the $\kappa_{\text {III }}$ phase occurs at the boundaries of the $\alpha$ grains, it is shaped by them, resulting in the microstructure shown in Figs. 5c and 6c.

\subsection{Effect of ECAP and heat treatment on mechanical properties}

The mechanical properties of ECAP processed NAB are dependent on both the $\kappa$ phase and grain structures. In particular, an effective refinement of the lamellar phase is crucial to enhance ductility in NAB. This is most clearly evidenced by the differences in mechanical properties between samples processed by route $\mathrm{C}$ (Fig. 9a) and route $\mathrm{B}_{\mathrm{A}}$ (Fig. 9b). Although both display 
similar $\mathrm{HV}$ values (Fig. 7), the superior ability of route $\mathrm{B}_{\mathrm{A}}$ to produce a homogeneous microstructure without any lamellar $\kappa_{\text {III }}$ leads to a significantly greater ductility after 4 passes compared to route $\mathrm{C}$ (Fig. 9). In route $\mathrm{C}$, the remaining lamellae would provide opportunities for stress concentrations and easy paths for fracture, both contributing to early failure. In contrast, when single phase aluminium bronze was ECAP processed [12], slight decreases in ductility were observed with increasing number of passes (route $\mathrm{B}_{\mathrm{C}}$ though). This implies that the increase in ductility gained through the homogenisation of the NAB microstructure is greater than the ductility loss due to a higher level of defects as a result of SPD. This point is further emphasised when comparing the tensile properties in the as-received NAB to those after 4 passes of ECAP in route $\mathrm{B}_{\mathrm{A}}$ and then heat treatment at $700^{\circ} \mathrm{C}$. The ECAP processed and heat treated sample is not only much stronger, but also possesses a greater ductility, $\sim 8 \%$ higher than the as-received material.

The decrease in yield strength or hardness after heat treatment was less significant with increasing number of passes, especially with route $\mathrm{B}_{\mathrm{A}}(\sim 430 \mathrm{MPa}, \sim 440 \mathrm{MPa}$ and $\sim 570 \mathrm{MPa}$ in the 1-, 2- and 4-pass samples after heat treatment at $700^{\circ} \mathrm{C}$ ). This is most likely due to the different softening processes. Significant recrystallisation may have occurred in the 1-pass sample as evidenced by the S-shaped curve in Fig. 8b. In contrast, the more linear curve for the 4-pass sample suggests grain growth as the dominant process. Detailed grain structure investigation is in progress to verify this point.

ECAP processed NAB is stronger than the ECAP processed aluminium bronze [12], and comparable in strength to aluminium bronze processed by high pressure torsion (HPT) [14]. The aluminium bronze in both cases had been processed at room temperature, significantly lower than the $400^{\circ} \mathrm{C}$ processing temperature in the present work. This increased strength may have resulted from a combination of increased solid solution content in the $\alpha$ phase and strengthening originating from the $\kappa$ phases. After heat treatment, ECAP processed NAB retains the same strength as that of the as-ECAP processed aluminium bronze but does not suffer from strain softening which is 
expected in HPT processed aluminium bronze due to its much smaller grain sizes. Therefore, this current study points to the potential of using a combination of ECAP and heat treatment for producing high strength NAB with good ductility.

\section{Summary and conclusions}

(1) Cast NAB was processed by ECAP at $400^{\circ} \mathrm{C}$ for up to 4 passes using routes $\mathrm{B}_{\mathrm{A}}$ and $\mathrm{C}$, respectively. Route $\mathrm{B}_{\mathrm{A}}$ proved to be more efficient at breaking the lamellar structure and producing a fine dispersion of refined $\kappa_{\mathrm{III}}$ uniformly distributed in the $\alpha$ matrix, leading to a significantly enhanced yield strength of $960 \mathrm{MPa}$ with a good tensile elongation of $\sim 14 \%$ after 4 passes.

(2) The ECAP processed NAB was subsequently subjected to isothermal heat treatments at temperatures between 300 and $800^{\circ} \mathrm{C}$. Although it had caused increasing drop in strength with increasing temperature, the heat treatment considerably improved the ductility and eliminated the work softening when conducted at $\geq 500^{\circ} \mathrm{C}$. The best combination of tensile properties was achieved in NAB processed for 4 passes with $\mathrm{B}_{\mathrm{A}}$ after heat treatment at $600-700^{\circ} \mathrm{C}$, with yield strength of 500 to $700 \mathrm{MPa}$ and elongation of $>30 \%$, greatly exceeding $<200 \mathrm{MPa}$ and $\sim 25 \%$ in the as-received NAB.

(3) The break-down of the lamellar $\kappa_{\text {III }}$ was initiated during ECAP through fragmentation of the laths under tension and spheroidisation at highly curved sections. The spheroidisation process continued during heat treatment, especially at $\geq 600^{\circ} \mathrm{C}$, leading to the complete disappearance of the lamellar $\kappa_{\mathrm{III}}$ in the material processed for 4 passes in $\mathrm{B}_{\mathrm{A}}$.

(4) At the highest heat treating temperature of $800^{\circ} \mathrm{C}$, both the fragmented and still lamellar $\kappa_{\text {III }}$ in all the ECAP processed materials spheroidised and coarsened into a globular morphology 
located between the $\alpha$ grains, probably assisted by grain boundary migration. The fine $\kappa_{\mathrm{IV}}$ precipitates were also coarsened and may have transformed into the high temperature $\kappa_{\mathrm{V}}$ phase.

(5) No softening occurred during heat treatment at $\leq 400^{\circ} \mathrm{C}$ in all the materials and the threestage softening due to recovery, recrystallisation and grain growth was only obvious in the materials processed for one pass. With increasing number of passes, it seemed that grain growth became the more dominant softening process, especially in the material processed for 4 passes in $\mathrm{B}_{\mathrm{A}}$.

\section{Acknowledgements}

This research is supported by the Defence Materials Technology Centre (DMTC) in Melbourne, Australia. 


\section{Figure captions}

Figure $1 \quad$ Microstructure of the as-received NAB, showing various $\kappa$ phases.

Figure 2 Microstructures of NAB after ECAP at $400^{\circ} \mathrm{C}$ for 1 pass (the longitudinal direction of the specimen is horizontal), showing (a) fragmented (arrow 1 and inset) and spheroidised $\kappa_{\text {III }}$ (arrow 2) and (b) largely undeformed laths (hollow arrow) in a large

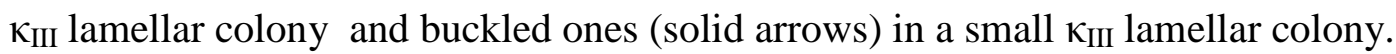

Figure 3 Microstructure of NAB after ECAP at $400^{\circ} \mathrm{C}$ for 4 passes in route $\mathrm{C}$ (the longitudinal direction of the specimen is horizontal), showing a partially transformed $\kappa_{\text {III }}$ structure with some spheroidised (arrow 1), some fragmented but then re-forming lamellae (arrow 2 and inset) and others fragmented and dispersed (arrow 3). Some $\kappa_{\text {II }}$ particles appeared to have collided (arrow 4).

Figure 4 Microstructure of $\mathrm{NAB}$ after $\mathrm{ECAP}$ at $400^{\circ} \mathrm{C}$ for 4 passes in route $\mathrm{B}_{\mathrm{A}}$ (the longitudinal direction of the specimen is horizontal), showing a completely transformed $\kappa_{\text {III }}$ structure with both fragmented and spheroidised $\kappa_{\text {III }}$ streams aligning in the direction of the principal strain, with the $\kappa_{\text {II }}$ particles becoming irregularly shaped (arrows).

Figure 5 Microstructures of NAB after ECAP at $400^{\circ} \mathrm{C}$ for 1 pass, followed by one-hour heat treatment at (a) 600 , (b) 700 and (c) $800^{\circ} \mathrm{C}$, showing increasingly transformed $\kappa$ phases. (The arrowed features are explained in the text.)

Figure 6 Microstructures of NAB after ECAP at $400^{\circ} \mathrm{C}$ for 4 passes in $\mathrm{B}_{\mathrm{A}}$, followed by onehour heat treatment at (a) 600, (b) 700 and (c) $800^{\circ} \mathrm{C}$, showing completely spheroidised and coarsened $\kappa_{\text {III }}$ at all the temperatures.

Figure $7 \quad$ Vickers microhardness versus the number of passes following ECAP at $400^{\circ} \mathrm{C}$ with routes $\mathrm{C}$ and $\mathrm{B}_{\mathrm{A}}$, respectively.

Figure 8 Vickers microhardness versus the isothermal heat treatment temperature for samples ECAP processed at $400^{\circ} \mathrm{C}$ for 1,2 and 4 passes following (a) route $\mathrm{C}$ and (b) route $\mathrm{B}_{\mathrm{A}}$.

Figure 9 Tensile stress-strain curves for $\mathrm{NAB}$ after ECAP at $400^{\circ} \mathrm{C}$ for 1,2 and 4 passes following (a) route $\mathrm{C}$ and (b) route $\mathrm{B}_{\mathrm{A}}$. The curves for as-received $\mathrm{NAB}$ are also presented for comparison.

Figure 10 Tensile stress-strain curves for NAB after ECAP at $400^{\circ} \mathrm{C}$ for (a) 1 , (b) 2 and (c) 4 passes with route $\mathrm{B}_{\mathrm{A}}$, followed by heat treatment at various temperatures for one hour. The curves for as-received NAB are also presented for comparison. 


\section{References:}

1. WHARTON, J. A., BARIK, R. C., KEAR, G., WOOD, R. J. K., STOKES, K. R., AND WALSH, F. C., Corr. Sci., 47 (2005) 3336-3367.

2. $\quad$ CULPAN, E. A., AND ROSE, G., J. Mater. Sci. 13 (1978) 1647-1657.

3. HASAN, F., JAHANAFROOZ, A., LORIMER, G. W., AND RIDLEY, N., Metall. Trans. A, 13 (1982) 1337-1345.

4. CUlPAN, E. A., AND BARNBY, J. T., J. Mater. Sci., 13 (1978) 323-328.

5. AL-HASHEM, A., AND RIAD, W., Mater. Char., 48 (2002) 37-41.

6. NI, D. R., XIAO, B. L., MA, Z. Y., QIAO, Y. X., AND ZHENG, Y. G., Corr. Sci., 52 (2010) 1610-1617.

7. WHARTON, J. A., AND STOKES, K. R., Electrochimica Acta, 53 (2008) 2463-2473.

8. $\quad$ RALSTON, K. D., AND BIRBILIS, N., Corrosion, 66 (2010) 75005.

9. RALSTON, K. D., BIRBILIS, N., AND DAVIES, C. H. J., Scr. Mater., 63 (2010) 12011204.

10. VAliEV, R. Z., AND LANGDON, T. G., Prog. Mater. Sci., 51 (2006) 881-981.

11. MISHRA, A., KAD, B. K., GREGORI, F., AND MEYERS, M. A., Acta Mater., 55 (2007) 13-28.

12. QU, S., AN, X. H., YANG, H. J., HUANG, C. X., YANG, G., ZANG, Q. S., WANG, Z. G., WU, S. D. AND ZHANG, Z. F., Acta Mater., 57 (2009) 1586-1601.

13. AN, X. H., QU, S., WU, S. D., AND ZHANG, Z. F., J. Mater. Res., 26 (2011) 407.

14. AN, X. H., WU, S. D., ZHANG, Z. F., FIGUEIREDO, R. B., GAO, N., AND LANGDON, T. G., Scr. Mater., 66 (2012) 227-230.

15. WANG, J., KANG, S. B., AND KIM, H. W., Mater. Sci. Eng. A, 383 (2004) 356-361.

16. SHIN, D. H., HAN, S. Y., PARK, K. T., KIM, Y. S., AND PAIK, Y. N., Mater. Trans., 44 (2003) 1630-1635.

17. MA, L. W., AND XIA, K., Kovove Mater., 49 (2011) 23-27.

18. HE, T., XIONG, Y., REN, F., GUO, Z., AND VOLINSKY, A. A., Mater. Sci. Eng. A., 535 (2012) 306-310.

19. MA, E., Scr. Mater., 49 (2003) 663-668.

20. XIA, K., AND WANG, J., Metall. Mater. Trans. A, 32 (2001) 2639-2647.

21. NOEBE, R. D., BOWMAN, R. R., AND NATHAL, M. V., Int. Mater. Rev., 38 (1993) 193232.

22. $\quad$ KIM, H. S., J. Mater. Res, 17 (2002) 173-179.

23. TIAN, Y. Z., DUAN, Q. Q., YANG, H. J., ZOU, H. F., YANG, G., WU, S. D., AND ZHANG, Z. F., Metall. Mater. Trans. A, 41 (2010) 2290-2303.

24. VOORHEES, P. W., J. Stat. Phys., 38 (1985) 231-252.

25. ASHBY, M. F., AND GENTAMORE, R. M. A., Acta Metall., 16 (1968) 1081-1092.

26. RANDLE, V., AND RALPH, B., Acta Metall., 34 (1986) 891-898. 

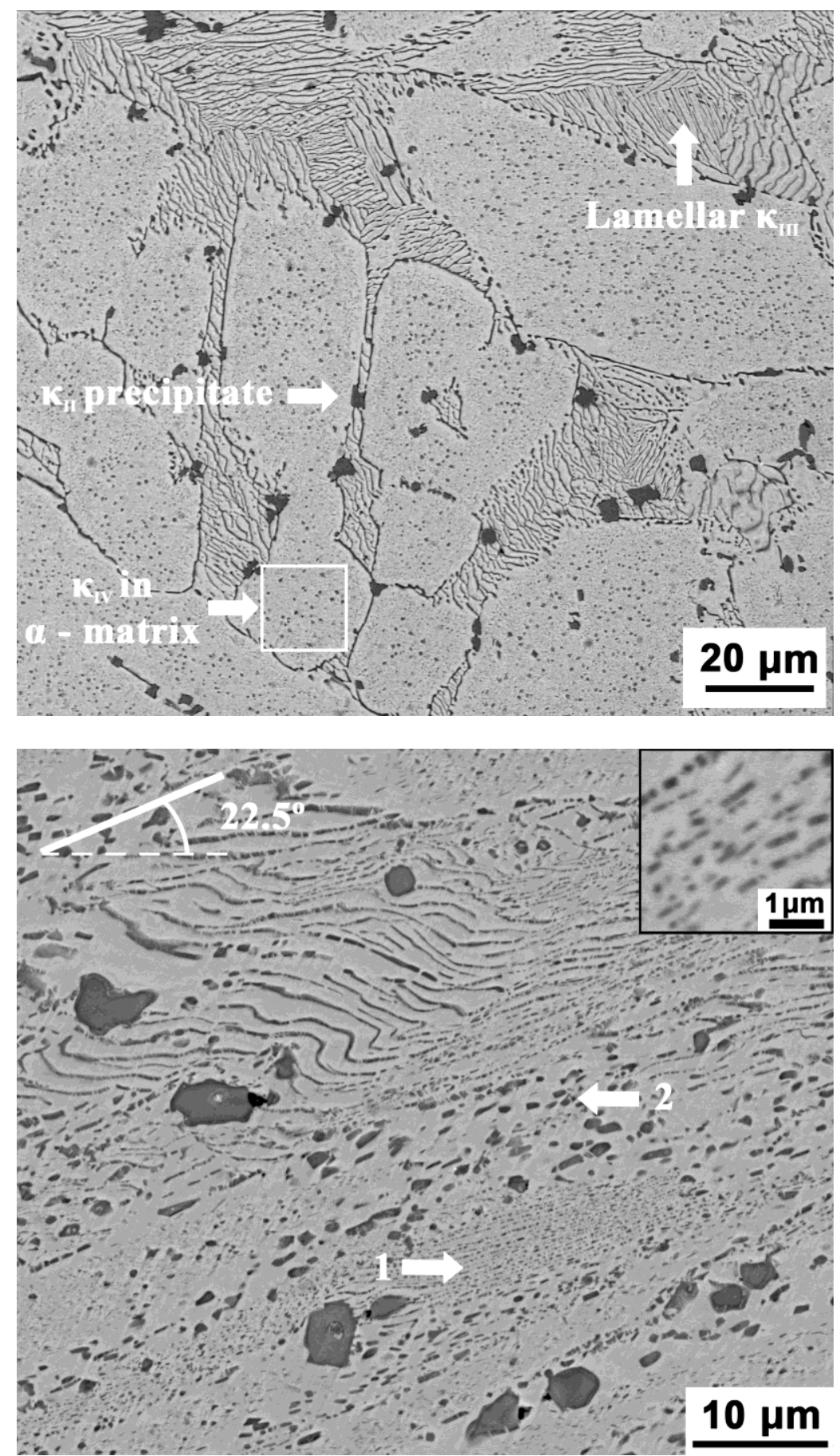

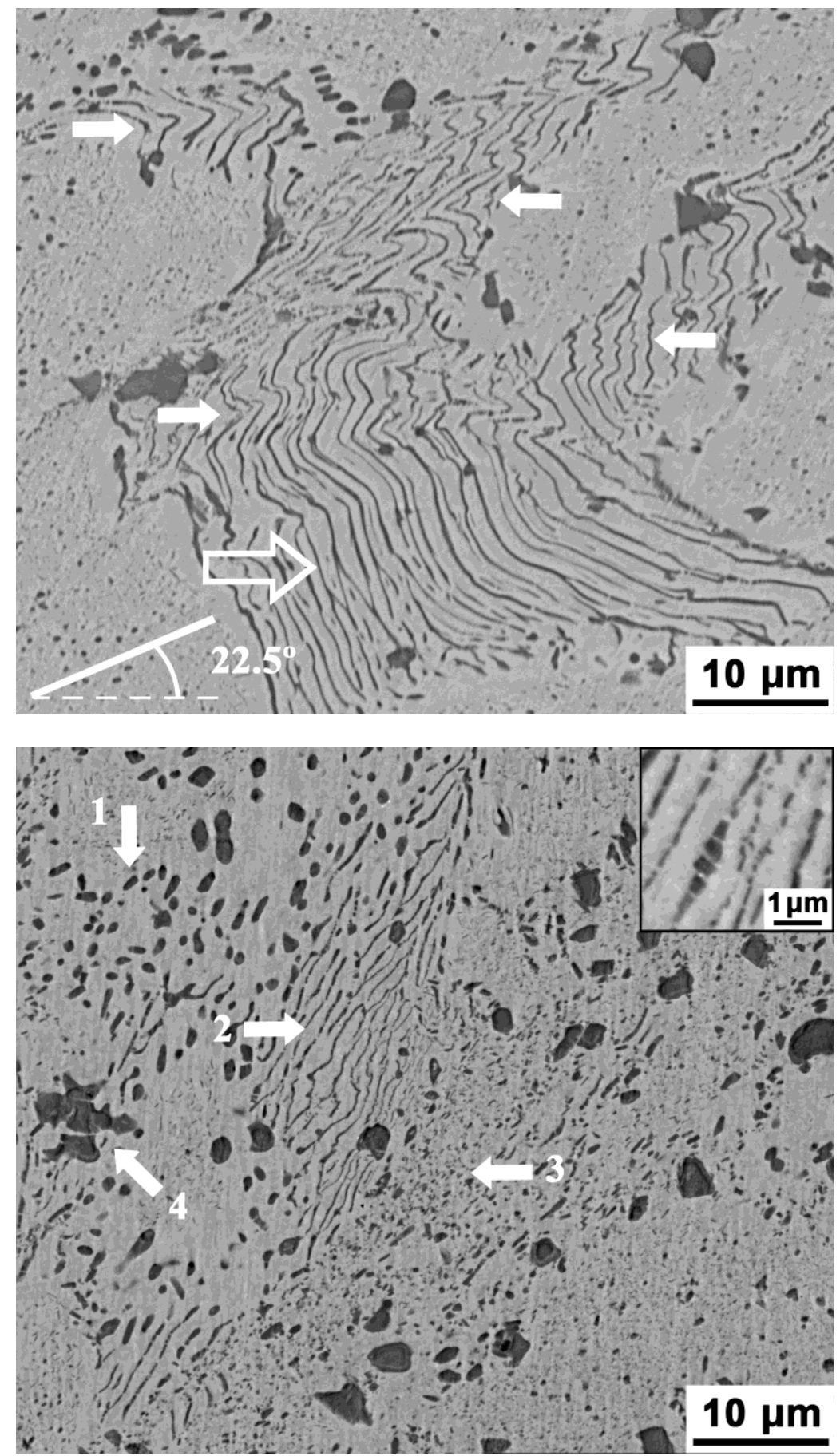

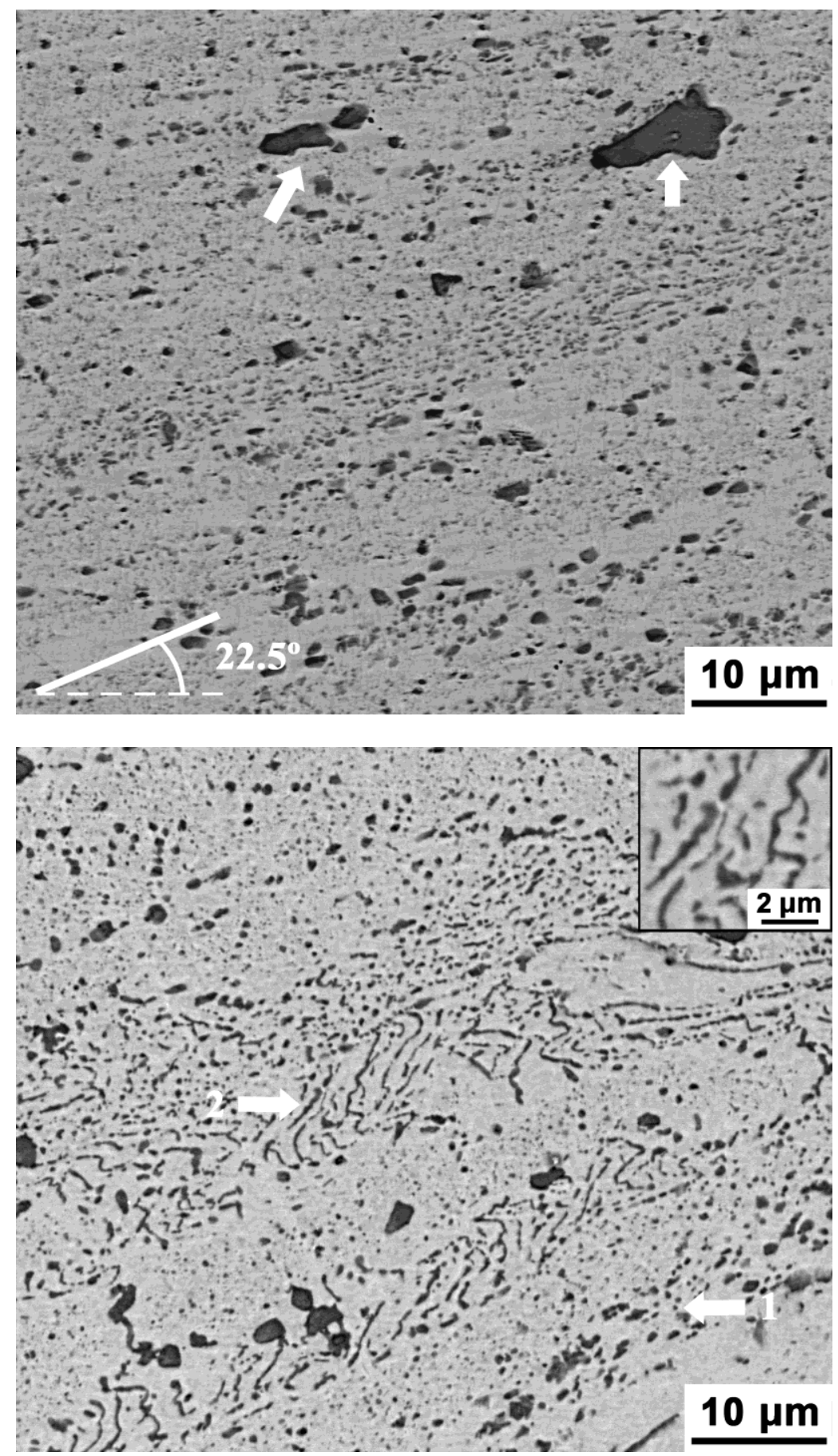

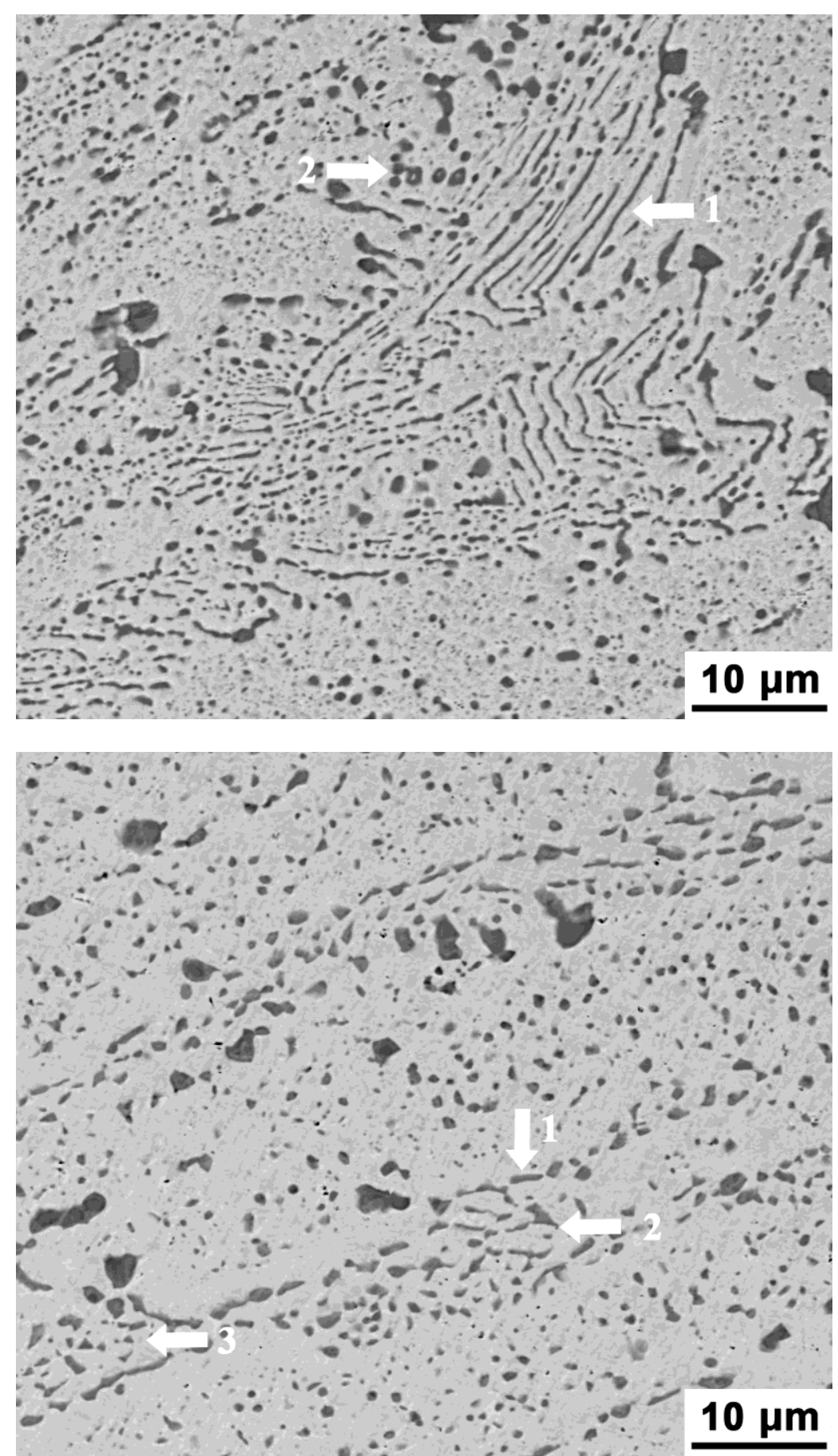

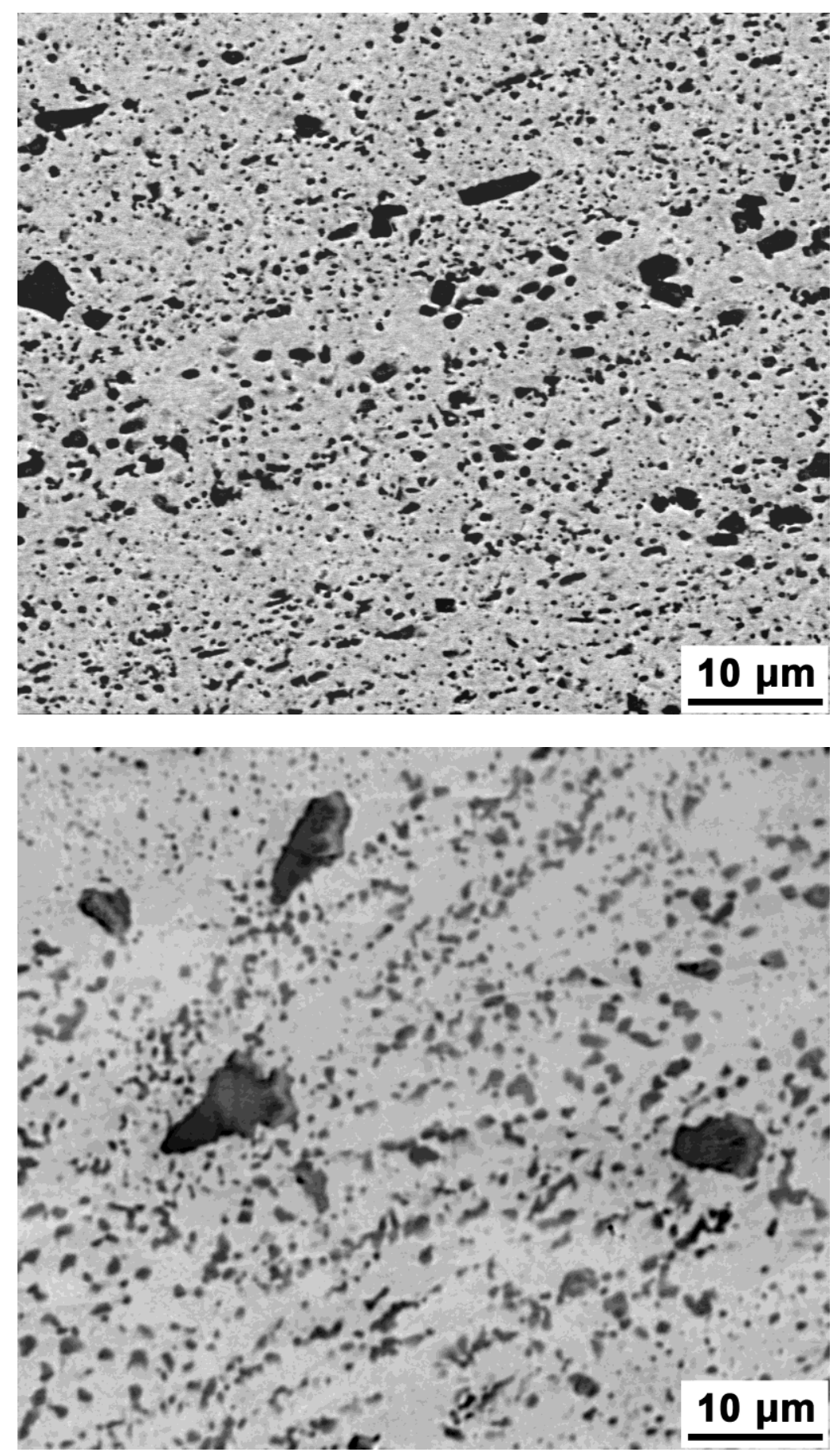

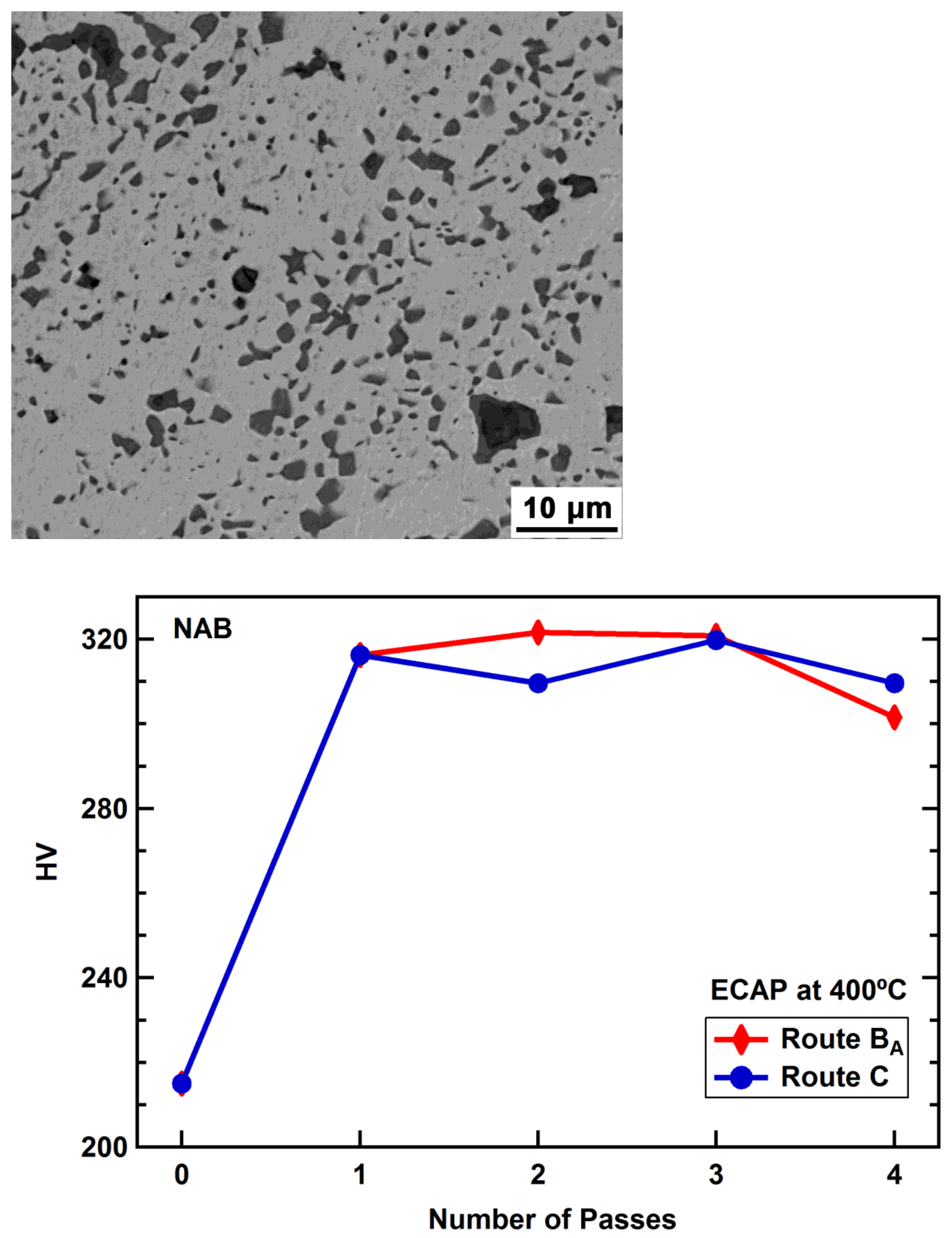

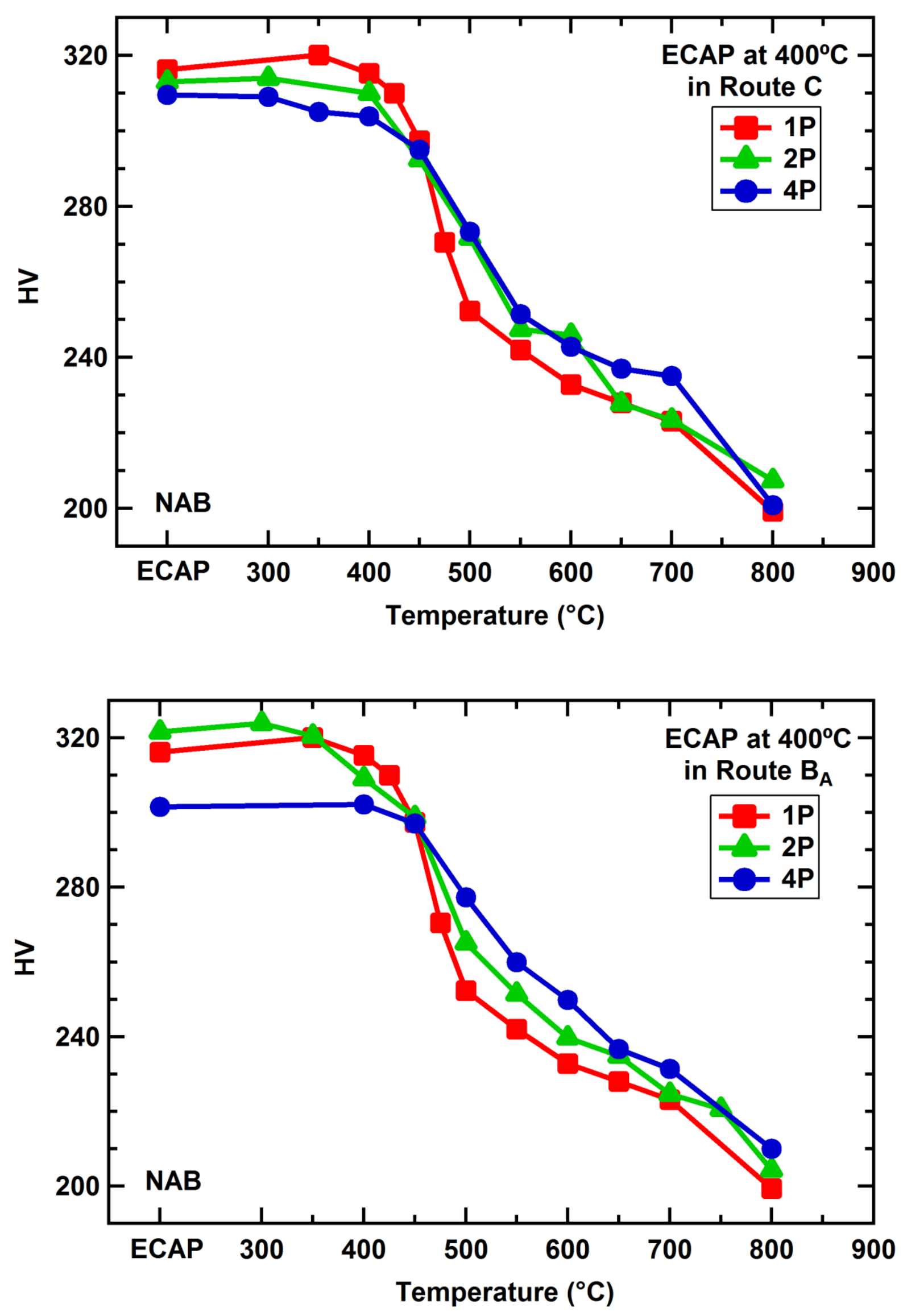

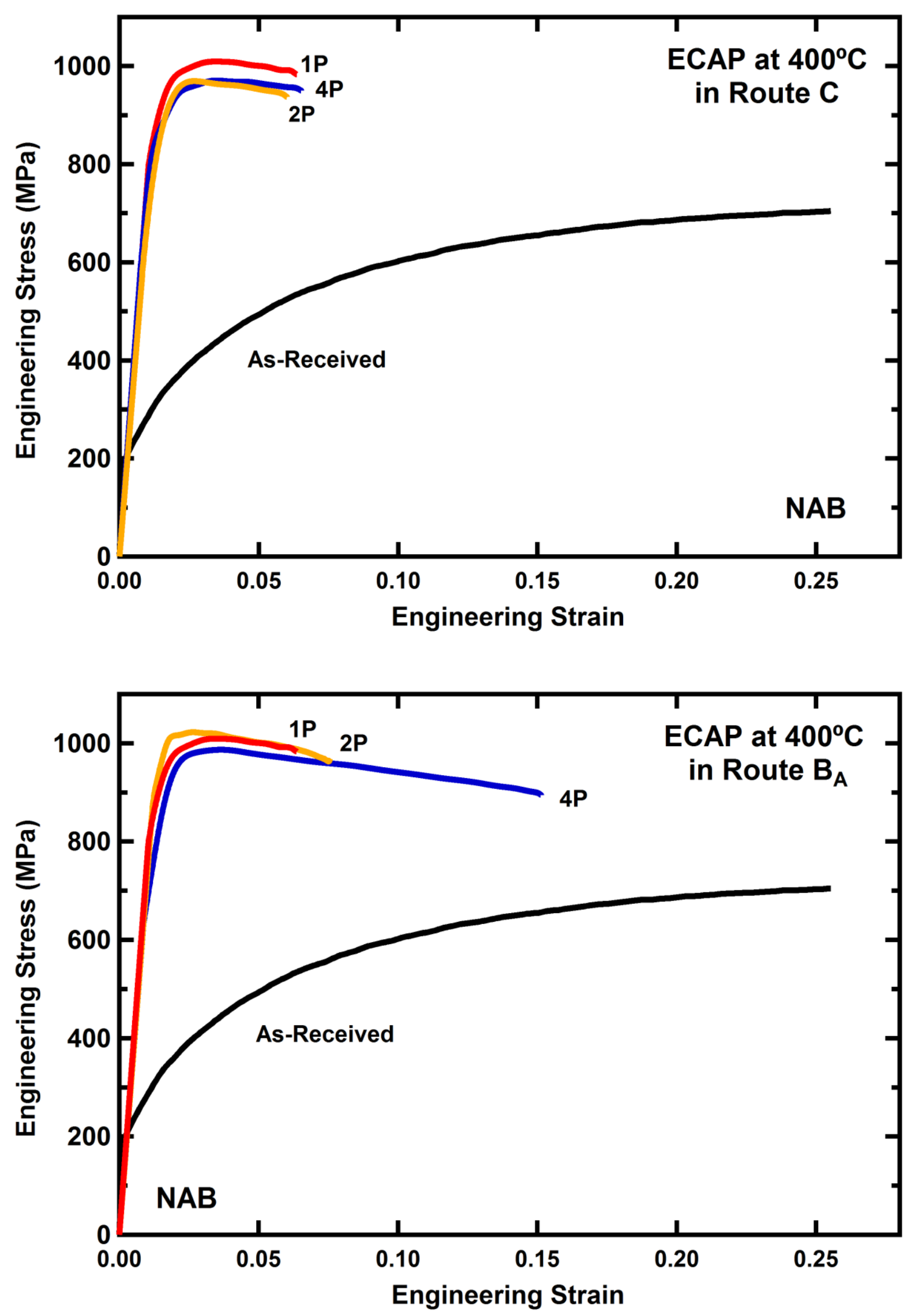

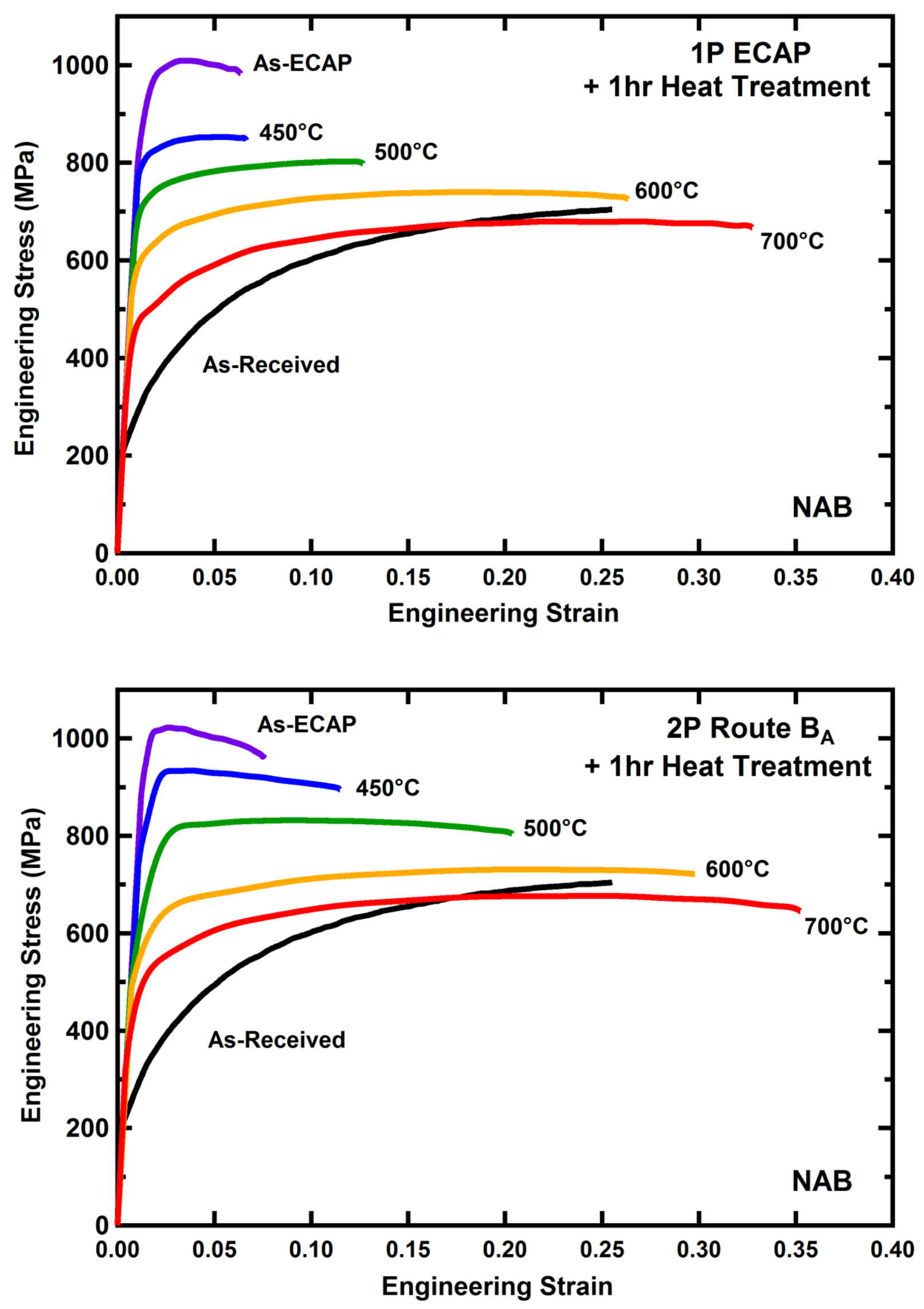


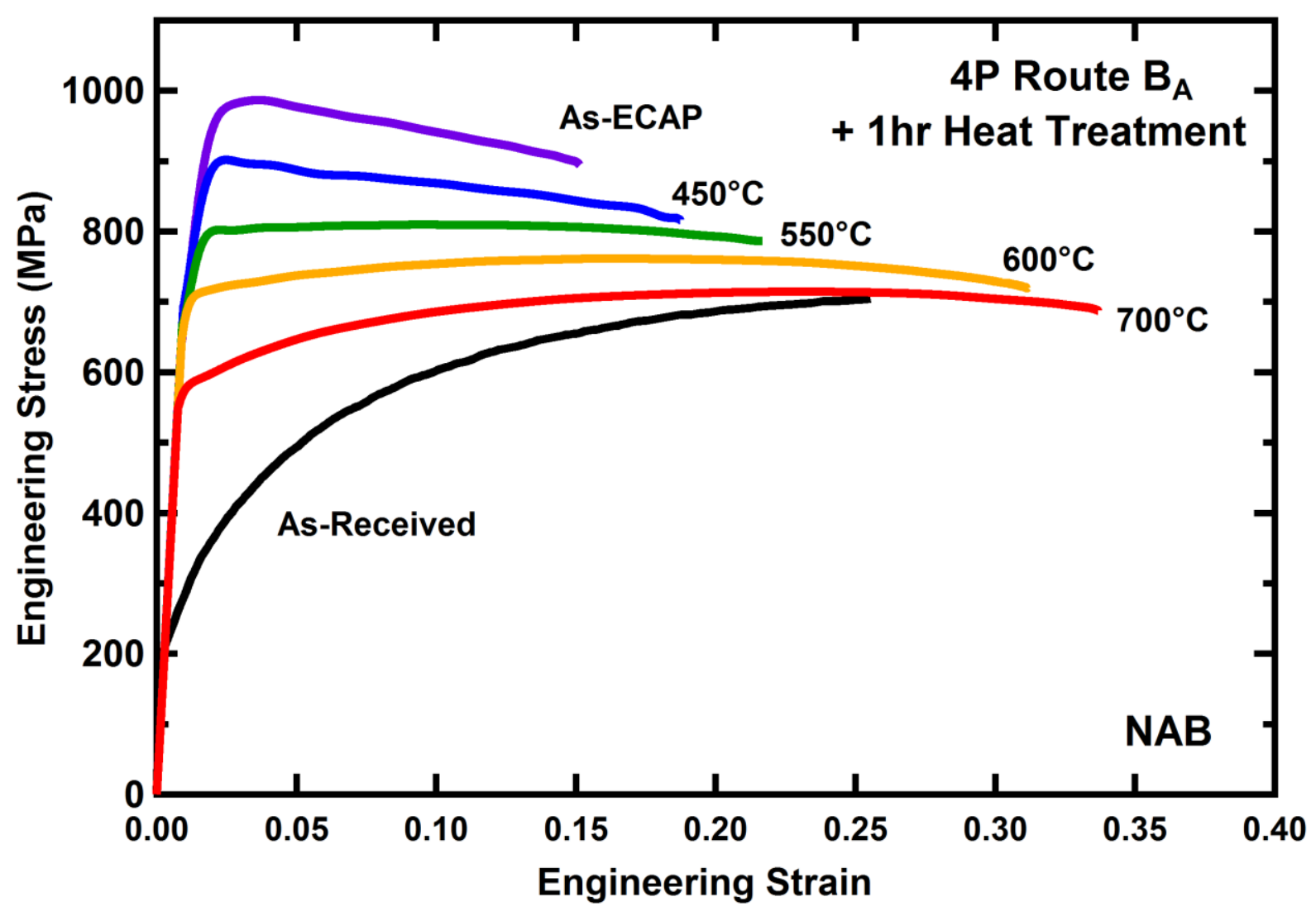




\section{University Library}

\section{- M M N E R VA A gateway to Melbourne's research publications}

Minerva Access is the Institutional Repository of The University of Melbourne

Author/s:

Barr, CJ;McDonald, DT;Xia, K

Title:

Significantly enhanced tensile strength and ductility in nickel aluminium bronze by equal channel angular pressing and subsequent heat treatment

Date:

2013-07-01

Citation:

Barr, C. J., McDonald, D. T. \& Xia, K. (2013). Significantly enhanced tensile strength and ductility in nickel aluminium bronze by equal channel angular pressing and subsequent heat treatment. JOURNAL OF MATERIALS SCIENCE, 48 (13), pp.4749-4757. https:// doi.org/10.1007/s10853-013-7256-2.

Persistent Link:

http://hdl.handle.net/11343/282714 